\title{
POLITIKK
}

SKANDINAVISK TIDSSKRIFT

FOR INTERNASIONALE STUDIER

Årgang 76, Nummer 3, side 217-234, 2018, ISSN 1891-1757, www.tidsskriftet-ip.no, Publisert oktober 2018

\section{Mot eit eksplisitt og sjølvbevisst kulturdiplomati}

\author{
Ola K. Berge \\ Seniorforsker, Telemarksforsking
}

\begin{abstract}
Samandrag
Når blei norsk kulturdiplomati sjølvmedvete og eksplisitt? Har kultur og kulturpolitikk nokon gong vore ein reelt integrert del av norsk utanrikspolitikk eller den utanrikspolitiske diskursen? Det er spørsmålet som blir diskutert i denne artikkelen, som samstundes reflekterer over korleis kultur heilt sidan 1800-talet har vore sentral del av konstruksjonen av Noreg som nasjon, og framleis er det, både i utanriks- og innanrikspolitisk samanheng. Kanskje er ikkje vegen frå norsk deltaking i verdsutstillinga i Paris i 1889 til korleis Noreg profilerer operaen i Bjørvika, teikna av Snøhetta, i dag, særleg lang? Artikkelen konkluderer likevel med at gjennomslaget for eit eksplisitt sjølvmedvete kulturdiplomati paradoksalt nok kan knytast til tida då ansvaret for norsk utanrikskulturell verksemd blei flytta $u t$ av UD og over til sju av kunstfeltets organisasjonar. Artikkelen er ei omarbeiding av prøveførelesinga som var del av forsvaret for PhD-graden i kulturstudiar ved HSN, med tittelen Look to Norway, current Norwegian Foreign Cultural Policy.
\end{abstract}

Nøkkelord: kulturdiplomati · utanrikskulturell verksemd • UD

\section{Mot eit eksplisitt og sjølvmedvete kulturdiplomati: Døme frå norsk utanrikspolitisk historie}

I denne artikkelen er norsk kulturdiplomati tema, då med utgangspunkt i spørsmålet om når dette blei ein eksplisitt og sjølvmedveten del av norsk utanrikspolitikk, eller om ein vil, den norske utanrikspolitiske diskursen. For å nærme meg denne tematikken går eg omlag eitt år tilbake i tid, til slutten av september 2017, då dåverande kultur- og utanriksministrar, Linda Hofstad Helleland og Børge Brende, i

\footnotetext{
^Kontaktinformasjon: Ola K. Berge, Email: berge@tmforsk.no

(C) 2018 Ola K. Berge. This is an Open Access article distributed under the terms of the Creative Commons Attribution 4.0 International License (http://creativecommons.org/licenses/by/4.0/), allowing third parties to copy and redistribute the material in any medium or format and to remix, transform, and build upon the material for any purpose, even commercially, provided the original work is properly cited and states its license.

Citation: Ola K. Berge (2018). Mot eit eksplisitt og sjolvbevisst kulturdiplomati, 76: 217-234. http://dx. doi.org/10.23865/intpol. v76.1237
} 
fellesskap inviterte til ei spesiell mottaking i regjeringa sin offisielle residens i Parkveien i Oslo.

Formålet med mottakinga var å feire norske kunstnarar og kulturarbeidarar med internasjonal suksess. Kunstnarar som, ifølgje kulturministeren, alle hadde «gjort det godt i utlandet og vært med på å sette Norge på kartet på en positiv måte». «Vi er i Norge flinke til å hylle idrettsutøvere. Vi bør bli flinkere til å anerkjenne hva kunstnerne våre klarer å få til ute», sa Helleland då ho ynskte velkommen. "Til tross for mye kritikk i sosiale medier, var det ingen sure ansikter å spore da regjeringen med kulturminister Linda Hofstad Helleland i spissen, inviterte til hyllest av den norske kultureliten tirsdag», kunne VG fortelje, og omlag 250 gjester frå eit stort utval av kunstsjangrar møtte opp. Kritikken VG refererte til, hadde kome frå røyster i kulturlivet, som meinte at denne festen var ein vel lettvint gest frå ei regjering som i liten grad tek internasjonaliseringa av norsk kunst og kultur på verkeleg alvor. Trass i dette, og trass i at heller ikkje denne mottakinga kom med særleg nytt om politiske satsingar på feltet, var dei frammøtte, som filmskapar Harald Zwart, musikarbrørne Marcus og Martinus, forfattar Åsne Seierstad og det norske black metal-bandet Mayhem, alle godt nøgde med arrangementet. "En flott fest og hyggelig for oss som sitter og jobber så mye alene», sa krimforfattar Unni Lindell til VG. ${ }^{1}$

$\mathrm{Og}$ innan internasjonalt kunst- og kulturarbeid har det dei siste åra vore mange suksessar å feire. Det er såleis ikkje berre ein «hype» i media når det blir hevda at norsk kunst og norske kunstnarar er meir internasjonalt aktive og populære enn nokon gong. For eit kunst- og kulturliv der internasjonalt gjennomslag er ein viktig indikator på stoda for kulturfeltet, er suksessen heilt sikkert stimulerande. For politikarar og andre med klokketru på den næringspolitiske verdien av kultureksport, kan det likevel vere på sin plass med ei forsiktig realitetsorientering. Ifølgje Rambøll, som på oppdrag frå Kulturrådet har estimert eksportverdien av dei fire store kunstområda musikk, litteratur, visuell kunst og scenekunst, var denne i 2016 på omlag 1,2 milliardar (Halmrast et. al. 2017) Dette er til samanlikning, ifølgje SSB, litt mindre enn verdien av den norske eksporten av prefabrikkerte bygnader dette året (NOK 1433 mill.), og litt meir enn verdien av eksport av klede og sko (NOK 887 mill.). Og då snakkar me dessutan om dei kunstformene som faktisk har ein tilnærma industriell profil, noko som igjen peikar mot at sjølv om norsk eksport av kulturprodukt har ein viss eksportverdi, er han relativt liten. Eksport av norsk kultur er altså ikkje den nye oljen. Det tyder sjølvsagt ikkje at ikkje slike eksportinntekter kjem godt med for dei aktørane som tener dei, og det tyder sjølvsagt heller ikkje at ikkje norsk kultureksport kan ha annan verdi enn den ein kan telje direkte i kroner og øre.

Sjølv om mange av gjestene frå kulturlivet nok hadde eit håp om at kvelden skulle bringe kulturpolitiske nyhende som del av opplegget, hadde kulturministeren få planar for framtidige internasjonale kultursatsingar å by på. For trass i at både VG og Dagsavisen skreiv at dette var minister Helleland sitt party, ligg ikkje den

\footnotetext{
${ }^{1}$ VG 26.09.2017. Disse dukket opp på kulturministerens minglefest.
} 
utanrikskulturelle politikken på Kulturdepartementet sitt bord, i alle fall ikkje den utanfor Norden. Derimot høyrer han til Utanriksdepartementet (UD) og diplomatiet. Mange kunstnarar veit det, og kanskje er det grunnen til at dei flokka seg vonfulle rundt representanten frå UD då ho kom inn på podiet for å snakke til forsamlinga. Og når eg skriv ho, er det ikkje fordi Noreg no har ein kvinneleg utanriksminister. Det er fordi han som inviterte til fest, Børge Brende, ikkje var der. Det var heller ikkje fyrste gong, i samanhengar der kultur står på den utanrikspolitiske dagsorden. I staden møtte statssekretær Tone Skogen.

Skogen understreka i si tale at kunst og kunstnarar reiser. At dei alltid har gjort det. Men raskare og oftare no, på grunn av ny kommunikasjonsteknologi. Ho hevda at kunst både gleder og provoserer, og at han har kapasitet til å sette undertrykte fri og få undertrykkarar til å skjelve. At kultur ikkje er kroner i kassa, fritid eller arbeidsplassar, men at det kan vere det $o g$. Kultur er, sa ho, alt det som gjer oss til menneske. Ei retteleg festtale, med andre ord. Men statssekretæren kom også inn på dei meir utanrikspolitiske sidene ved departementets kulturengasjement, noko som peikar fram mot det som er tema for denne artikkelen.

Når kulturen sprenger grenser, flettes nasjoner sammen. I likhet med diplomatiet handler kulturen om å skape tillit og trygghet gjennom samspill - gjennom å bli kjent med hverandre og vise hvem vi er. Men kultur er ikke diplomatiets forlengede arm. Kultur er diplomati. Diplomati med løyve - og noen ganger plikt - til å provosere. En av Utenriksdepartementets fremste plikter - og privilegier - er å fremme norsk kultur. ${ }^{2}$

«Men først og fremst er det dere», sa statssekretæren og peika mot dei frammøtte kunstnarane, "som fremmer Norge».

Skogen si tale blei møtt med høfleg akklamasjon. Heller ikkje utanriksdepartementet sin representant syntest å vekkje publikummet, som på dette tidspunktet for alvor hadde kome i hyggeleg passiar med kvarandre. Kanskje ville ho og ha fått meir entusiastisk respons, hadde det ikkje vore for den litt fjerne rolla kultur og kulturpolitikken speler i utanrikspolitikken. Altså i den verkelege utanrikspolitikken. Der ordet «kultur» ikkje blir nemnt ein einaste gong i utanriksminister Brende si meir enn ein time lange utanrikspolitiske utgreiing for Stortinget i 2017 (og heller ikkje i 2016, og sannsynligvis ikkje i 2015), korkje i tydinga kunst og kultur som ytring eller i antropologisk tyding, kultur som levemåte eller uttrykk for identitet.

Både Hofstad Helleland og Skogen ville kanskje også fått ein meir entusiastisk respons, hadde det ikkje vore for kritikken både kultur- og utanriksdepartementet har møtt, for å vere i overkant instrumentelt opptekne av kultur som ncering i utanrikskulturelle saker. Eller som kommentator Geir Rakvaag i Dagsavisen skreiv i forkant av mottakinga: «Mottakelsen i dag er et uttrykk for at kunsten først og fremst skal være et instrument for å bedre handelsbalansen med utlandet». ${ }^{3}$

\footnotetext{
${ }^{2}$ Transkripsjon av statssekretær Skogen si tale, innvilga utlevert frå UD 29.09.2017.

${ }^{3}$ Dagsavisen, 26.09.2017. Kjendisfest hos kulturministeren.
} 
Trass i få lovnadar om konkrete politiske satsingar framover - tvert om, i statsbudsjettet presentert av regjeringa berre litt over ei veke seinare, var løyvinga til utanrikskulturell aktivitet kutta med $40 \%$ - var det eit heilt klart sjølvsikkert og sjølvmedvete kunstfelt som fordøydde mottakinga i regjeringa sin representasjonsbustad denne haustkvelden. Men også statssekretæren frå UD verka sjølvmedveten, som representant for eit departement som i alle fall her kommuniserte kultur som ein naturleg og nødvendig del av norsk utanrikspolitikk og diplomati. Med eller utan utanriksministeren til stades.

I kva grad denne sjølvmedvetne haldninga spring ut av, eller er integrert i norsk diplomati, og eventuelt på kva tidspunkt i norsk diplomatisk historie eit slikt medvit blei eksplisitt, er tema for denne artikkelen. Den freistar å svare på følgjande spørsmål: Kultur har alltid vore del av diplomatiet, $i$ nyare tid synest kultur likevel å ha blitt eit meir eksplisitt og sjølvmedvete element $i$ norsk diplomatisk praksis. Når blei det norske kulturdiplomatiet eksplisitt og sjølvmedvete? Svaret på spørsmålet er sjølvsagt avhengig av kva ein meiner med eksplisitt og sjølvmedvete, og ikkje minst kva ein legg i omgrepet kulturdiplomati.

I det følgjande freistar eg å diskutere og svare på desse og andre liknande spørsmål og premiss, gjennom å drøfte korleis særleg fire historiske situasjonar kan sjåast som potensielle startpunkt for eit sjølvmedvete, eksplisitt norsk kulturdiplomati, men også korleis dei kan sjåast som nodalpunkt i ein meir djuptgripande kulturdiplomatisk arkeologi, der dei kvar for seg indikerer diskursar som er mogleg og analytisk fruktbart å skilje og analysere.

For raskt å kunne semjast om kva det er me snakkar om når me snakkar om kulturdiplomati, kan det innleiingsvis vere nyttig å presentere det ei rad ulike forskarar refererer til som ein standarddefinisjon på kulturelt diplomati: "The exchange of ideas, knowledge, art and other aspects of culture between states and people in order to generate mutual understanding.» (Cummings 2003, Nisbett 2012, Rostgaard 2011, Waller 2007 m.fl.) Denne definisjonen er imidlertid nokså snever, då han i hovudsak knyter an til kulturell forståing. Statsvitaren Simon Mark byr på ein meir utvikla definisjon når han skriv: "Cultural diplomacy is carried out by a government to support its foreign policy goals or diplomacy (or both) by using a wide range of cultural manifestations for a variety of purposes.» (2008: ii) Døme på slike bruksområde er, ifølgje Mark:

It helps advance national interests, contributes to a government's diplomacy, and enhances mutual understanding between countries and their peoples. Cultural diplomacy also raises a state's profile, helps counter negative impacts of contentious issues, 'puts the record straight', and is now more frequently implicated in contributing to governmental efforts to 'brand' a state. The practice supports efforts to protect a national culture in order to counter the impact of cultural 'invasion.' Cultural diplomacy is also undertaken in order to attain domestic objectives. (2008: 4-5)

Men kulturdiplomati blir ikkje nødvendigvis del av norsk utanrikspolitikk berre fordi diplomatar eller andre av UDs byråkratar er involverte i aktiviteten. Eller, for den 
saks skuld, fordi deler av denne aktiviteten finn stad i utlandet. Han vil nødvendigvis vere del av det ein kan omtale som den utanrikspolitiske diskursen, og dermed innanfor det ein kan sjå som relevant å drive utanrikspolitisk forsking på, men altså ikkje utan vidare sjølve utanrikspolitikken. Den manglande tyngda kultur og kulturpolitiske spørsmål blir vist i den utanrikspolitiske debatten t.d. på Stortinget, vitnar nettopp om det. Eit viktig spørsmål blir då: Korleis høyrer kulturpolitikken heime i det utanrikspolitiske mangfaldet? Høyrer han heime her i det heile? Svaret på det er ja. Kulturpolitikk er del av norsk utanrikspolitikk både i eksplisitt og implisitt forstand. Eksplisitt, sidan UD har eit overordna sektoransvar for alle Noregs samla interesser internasjonalt, også for kultur og kulturarbeidarar (kunstnarar); implisitt, sidan UD har eit spesifikt forvaltingsansvar for kulturpolitikk utanfor Noreg sine grenser.

Det er i hovudsak UD og Kulturdepartementet som har det sentrale forvaltningsansvaret for kulturpolitikk i Noreg. Ansvarsfordelinga har, som eg kjem attende til, historisk endra karakter i takt med eit aukande politisk behov for å forankre arbeidsoppgåver i relevante fagdepartement. Det har vidare endra seg i takt med kunstfeltet sine ynskjer og behov, som heilt sidan etter andre verdskrigen har blitt lytta til, i ein utprega korporativ norsk kulturpolitisk modell (Mangset 1997). Dagens arbeids- og ansvarsfordeling skriv seg frå St.meld. nr. 48 (2002-2003) Kulturpolitikk fram mot 2014, der det står at UD har «overordna ansvar for presentasjon av og informasjon om norsk kultur i utlandet og for gjensidig kultursamarbeid mellom Noreg og land i Sør». Kulturdepartementet har på si side eit "overordna ansvar for nordisk og multilateralt kultursamarbeid, dessutan for formidling av utanlandsk kultur til Noreg» (Kulturdepartementet 2003: 111). Enkelt sagt har UD ansvaret for eksport av norsk kultur ut av Noreg, medan Kulturdepartementet har ansvar for importen av kultur inn i landet.

Det at UD har eit eksplisitt kulturpolitisk ansvar, gjer altså kultur og kulturpolitikk til ein implisitt del av utanrikspolitikken. Men kultur kan også hevdast å vere del av utanrikspolitikken i meir direkte og eksplisitt utanrikspolitisk forstand. For det fyrste fordi utanrikspolitikken omfattar eit tverrsektorielt ansvar for alle norske interesser utanlands (inkludert enkeltkunstnarar, kulturorganisasjonar, -institusjonar og -bransje). Dette er imidlertid eit svakt argument for kulturen si rolle i utanrikspolitikken. Eit langt sterkare er at kunst og kultur i utanrikspolitisk så vel som i innanrikspolitisk samanheng blir knytt til eit vedvarande arbeid med å konstruere, artikulere, promotere og forsvare ein norsk nasjonal identitet (Leira et al. 2007, Berge 2017). I tillegg kan ein altså, om enn i avgrensa omfang, sjå kulturelle produkt som del av den totale norske internasjonale handelspolitikken, eit politikkområde som UD har eit vesentleg ansvar for. I sin giennomgang av det utanrikskulturelle feltet, frå 2000, samanfattar Lending (2000: 8) kulturen si eksplisitte rolle i utanrikspolitikken slik:

Internasjonalt kultursamarbeid fremstilles blant annet som

- konfliktforebyggende virksomhet som fremmer fred og mellommenneskelig forståelse 
- en "døråpner" for mellomstatlig dialog og minimumskontakt når klassisk diplomati ikke fører frem

- et næringspolitisk virkemiddel som fremmer landets økonomiske interesser

- et ledd i den nasjonale selvpresentasjonen, til fremme for kunnskap om og positive holdninger til landet i verden.

Dette er alle målsetjingar som blir trekt fram også i internasjonal forsking om kultur og kulturdiplomati som del av utanrikspolitikk (Wyszomirski, Burgess, and Peila 2003, Nisbett 2013, Belanger 1999, White 2012).

Den norske, samtidige utanrikskulturelle praksisen er vidare prega av ein kompleks struktur av aktørar og prosessar. Som eit bakteppe for den vidare diskusjonen kan ein rask presentasjon av dei viktigaste vere nyttig. Forutan plasseringa i UD og utanrikstenesta sjølv, er den utanrikskulturelle verksemda i dag for ein stor del delegert til sju kunstfaglege organisasjonar frå ulike delar av norsk kunst- og kulturliv. Dei sju, som utgjer grupperinga Norwegian Arts Abroad, er Office for Contemporary Art Norway, OCA, Music Norway, Norwegian Crafts, Norsk filminstitutt, Danse- og teatersentrum, NORLA, Senter for norsk litteratur $i$ utlandet og Design og arkitektur Norge, DogA. Særleg tre oppgåver står sentralt for dei sju: Fyrst, og kanskje viktigast, skal dei fungere som faginstans for UD i alle kunstfaglege spørsmål. Dette inneber også å legge til rette for såkalla ekspertvitjingar til Noreg, der utanlandsk presse og fagekspertar (t.d. kuratorar eller bransjerepresentantar) vitjar kulturarrangement i Noreg (gode døme her er Øyafestivalen i Oslo og Oktoberdans i Bergen). For det andre deler dei via sju underliggande fagutval ut reisestøtte til norske kunstnarar og kulturarbeidarar som jobbar internasjonalt. Til slutt forvaltar dei ein liten pott prosjektmidlar til strategisk bruk. I tillegg til desse sju inngår ei rad andre institusjonar i nettverket, m.a. alt nemnde Kulturrådet, men også festivalar, museum og visningsstader av både offentleg og privat karakter.

Ser ein til ansvarsdelinga mellom UD og Kulturdepartementet referert over, er det lett å tenkje at UD og utanrikstenesta si befatning med kunst og kultur er av relativt ny dato. Men stemmer det, er dette engasjementet nytt? For å nærme seg det ein kan sjå som eit fyrste potensielt nodalpunkt i norsk kulturdiplomati, kan ein heller følgje ideen om at kulturdiplomatiet ikkje er av ny dato i det heile, men tvert om like gamalt som diplomatiet sjølv.

\section{Pioner-år i kulturdiplomatiet}

Ifølgje kunstsosiolog Dag Solhjell er ei av dei lange linene i norsk kunstpolitikk frå 1814 «den store betydning Stortinget har tillagt norsk kunst og kultur for Norges internasjonale anseelse og nasjonale identitet» (2006: 59). Ifølgje Solhjell vidare, veks eit slikt utanrikskulturelt felt fram alt frå midten av 1800-talet, særleg med den norske deltakinga ved den andre store verdsutstillinga i London i 1851, også kjend som The Crystal Palace exhibition. Dei fyrste teikna til eit kulturdiplomati følgjer difor spora til norsk diplomati og norsk utanrikspolitikk sjølv. Det er heller ikkje urimeleg 
å påstå at dei to, altså kulturdiplomati og norsk diplomati generelt, på denne tida var to sider av same sak.

Det er sjølvsagt umogeleg å analysere framveksten av denne delen av utanrikspolitikken lausreve frå den generelle historiske konteksten han er del av. Særleg sentralt står kampen for autonomi. Etter at Kiel-traktaten og seinare Mossekonvensjonen i 1814 slo fast at Noreg, rett nok som eige kongedømme, skulle i union med Sverige, blei kampen for nasjonal sjølvstende den aller viktigaste saka i norsk politikk og samfunnsliv. Det å etablere uavhengige diplomatiske kontaktar internasjonalt blei samstundes både ei av dei mest presserande oppgåvene og betente konfliktsakene i tilhøvet mellom Noreg og Sverige i desse åra (Neumann \& Leira 2005).

Samstundes, tett vevd saman med kampen for sjølvstende, starta arbeidet med å konstruere den norske nasjonen og ein nasjonal identitet. Kva Noreg og det norske «var» eller skulle vere, var ikkje gitt, og alt frå politikarar, næringslivsleiarar, vitskapsmenn og kunstnarar til polarheltar og oppdagarar deltok i debatten (Brenna 2002). Til å byrje med gjekk eit slikt konstruksjonsarbeid føre mest innan ein nasjonal diskurs. Som Ernest Gellner (2006) peikar på som typisk, fell den gryande nasjonalismen saman i tid med utviklinga av Noreg som ein moderne nasjon, som resultat av industrialisering, ein utdanningsrevolusjon samt utviklinga av eit norsk embetsverk. Ein søkte eit fellesskap trass i ulike og stridande interesser, det Benedict Anderson (1991) berømt har kalla «imagined communities», altså eit fellesskap som er tenkt meir enn reelt. Men i eit klima der norsk nasjonalt sjølvstyre i stor grad kom til å vere avhengig av andre europeiske nasjonar, blei det viktig å konstruere eit tydeleg «Noreg» i desse nasjonane si bevisstheit. Det var med andre ord viktig å markere seg som ein sjølvstendig og udiskutabel nasjon ute blant dei som ein visste ville bli viktige allierte i den komande kampen om sjølvstende.

Her kan det også vere på sin plass å skjele til den britiske historikaren Eric Hobsbawm sine teoriar om the production of national states og hans understreking av nasjonalstaten både som eit relativt moderne konsept - særleg i den grad nasjon etter kvart kom til å bli einstydande med eit statleg og politisk rammeverk - og som ein konstruksjon kultivert av særskilde elitar (Hobsbawm 2012). Slike elitar kunne vere politiske, akademiske, økonomiske eller kunstnarlege. Vidare, ifølgje Hobsbawm, er utviklinga av nasjonale symbol og ritual eit ledd i denne konstruksjonen.

Den norske deltakinga i London i 1851, som altså var statleg initiert og finansiert, må sjåast i lys av dette. Ifølgje idéhistorikar Brita Brenna vitnar Noregs deltaking i dei fyrste verdsutstillingane om ein ung nasjon, ivrig etter å vise verda at han var sivilisert og moderne, ikkje ein nasjon av villmenn. Ifølgje Brenna var Noreg blant dei som sende representantar til alle verdsutstillingane mellom 1851 og 1900, i London, Paris, Chicago og Wien: «Nasjonens ære sto på spill i den kapitalistiske kappestriden og det gjaldt å manifestere vekst og fremskritt foran resten av verden.» (Brenna 2002) ${ }^{4}$ Det å t.d. syne fram verk av norske, moderne kunstnarar var ledd i denne strategien.

${ }^{4}$ https://forskning.no/kulturhistorie-moderne-historie/2008/02/norge-en-ivrig-nasjon-pa-1800-tallet 
Det var ikkje sjølvsagt kva det norske skulle vere, og kunst og kultur blei slik viktig i konstruksjonen av det moderne og sjølvstendige Noreg.

I arbeidet med å tydeleggjere ein norsk profil spelte kulturdiplomatiet ei viktig rolle. I desse fyrste tiåra av norsk utanriks kulturpolitikk var denne politikken imidlertid i stor grad implisitt. Me hugsar statssekretær Tone Skogen sine ord om at kultur er diplomati, og slik var det i desse fyrste åra. Datidas norske celebritetar vitskapsmenn, som Birkeland og Eide, oppdagarar, som Nansen, og kunstnarar, som Bjørnstjerne Bjørnson - blei raskt viktige ambassadørar for det sjølvstendige norske prosjektet. Dette hadde samanheng med at Noreg i union med Sverige enno ikkje hadde etablert ein sjølvstendig utanrikspolitikk (Bjørgo et. al. 1995). Utanrikstenesta for unionen var dominert av svenske byråkratar, noko som gjorde behovet for indirekte marknadsføring av norske posisjonar og syn viktig.

Den norske deltakinga på verdsutstillingane handla om å syne at ein som nasjon hengde med $\mathrm{i}$ internasjonal vekst og utvikling. Men i tillegg knytte deltakinga an også til ein annan dimensjon, nemleg å syne fram den norske kulturarven og identiteten. Dette blei sett som særleg viktig for å aksentuere Noreg som ein nasjon med ein lang historie, ikkje som ein nasjonal jypling eller haleheng til Sverige. Ein kan på denne tida også sjå ein klar samverknad mellom økonomiske, politiske og vitskapsteoretiske idear og trendar. Som følgje av etableringa og framveksten av nye disiplinar som historie, biologi, kunsthistorie og antropologi kunne ein no også sjå ein diskurs med fokus på teleologi og samanhengen og forholdet mellom fortid, notid og framtid vekse fram. Her blei både kulturarv og innovasjon sett som (likeverdig) viktige element for å vurdere eit gitt sivilisasjonsnivå. Dermed blei den unge nasjonen Noreg, framleis som del av unionen Noreg-Sverige, på dei fyrste verdsutstillingane presentert og promotert både som natur- og som kulturnasjon (Brenna 2002).

Den mest interessante av alle verdsutstillingane i denne perioden, for Noreg sin del, er truleg L'Exposition Universelle 1889 i Paris. For dei fleste er vel utstillinga kanskje mest kjend for det som var inngangsportalen, nemleg Eiffeltårnet. Men utstillinga er interessant nettopp fordi det var her Noreg for fyrste gong var representert med ein separat norsk paviljong, teikna av arkitekten Holger Sinding-Larsen. Ved tidlegare utstillingar hadde Noreg delt paviljong med unionspartnar Sverige. I 1889 derimot nekta svenskane å delta, etter sigande som ein slags protest på det revolusjonære temaet for utstillinga, nemleg 100-årsjubileet for den franske revolusjon i 1789. Sverige og den svenske kongefamilien hadde trass alt djupe røter i fransk kongemakt. Dette opna dermed for ein mildt revolusjonær norsk åleinedeltaking, med eigen paviljong. Tema for den norske deltakinga var Fridtjof Nansen og kampen mot naturkreftene. Melom anna blei ein modell av den nyleg opna fjellvegen $i$ Geiranger vist fram, og for dette dømet på ingeniørkunst som utfordrar naturelementa tok prosjektleiar Hans Hagerup imot gullmedalje.

Ein sentral aktør både $\mathrm{i}$ den norske deltakinga og i det norske diplomatiet på denne tida var vitskapsmannen og matematikaren professor Ole Jacob Broch. Broch, som elles er kjend m.a. som stortingsmann (1862-69) og statsråd i 
Marinedepartementet (1869-72), arbeidde dei siste ti åra av sitt liv for å få etablert eit felles internasjonalt vitskapeleg mål- og vektsystem. Denne tida oppheldt han seg hovudsakeleg i Sèvres utanfor Paris, der han i tillegg til det vitskaplege arbeidet hadde ei rad representasjons- og diplomatiske oppgåver for Noreg. I sin biografi om Broch, under overskrifta «Internasjonalisme og nasjonalisme», skriv Jens Arup Seip følgjande:

Brochs opptreden på den internasjonale scene ga maksimal virkning når det gjaldt å fremheve Norge som egen nasjon. Hans personlige stilling i det internasjonale miljø i Paris var sterk og lysende, og han la an på å opptre som norsk. Han kunne dermed på en og samme gang tilfredsstille sin egen forfengelighet, og den nasjonale. Det å vise seg selv, var å vise flagget. Han hadde glede ved begge deler. (1971: 649)

Ein annan viktig arena for markering av norsk sjølvstende der Broch var sentral, var altså dei store verdsutstillingane mot slutten av 1800-talet. Seip skriv:

På så mange måter ble selvstendigheten, ikke fellesskapet understreket i møtet med andre nasjoner. Et av de områder hvor dette skjedde, var de store verdensutstillinger. Norsk iver for å delta-tross omkostninger-var uttrykk for et ønske om å vise flagget. [...] Dette skjedde i stigende grad på utstillinger og kongresser i 1870-80-årene. Norge disponerte i 1878 til forargelse for svenskene like mye rom som Sverige. Norge var først ute med beslutningen om å delta, og Broch greide å legge hånd på halvparten av gulvplassen. Sverige var tilbakeholdende når det gjaldt utstillinger som hadde sete i republikkens Paris. Og ved verdensutstillingen i 1889-hundreåret etter revolusjonen—ønsket svenskene ikke å delta. De satte dermed Norge i den ettertraktede stilling å opptre alene for verdens Øyne, som en svensk iakttager uttrykte det. [Ibid.]

Broch og hans verksemd er slik, som Seip poengterer, eit godt døme på korleis norsk vitskap, kunst og politikk på denne tida hadde som strategi å fremje nasjonalisme igjennom internasjonalisme. Broch er dessutan eit svært godt døme på korleis det norske diplomatiet som arbeidde med ein slik strategi var ei blanding av meir og mindre offisielle aktørar. Slik kan ein tale om eit utvida eller hybrid diplomatisk korps med uviss institusjonell forankring, som samstundes som det var svært effektivt var vanskeleg for unionsforkjemparane å kritisere. I og med at fleire av desse kvasidiplomatane var kunstnarar og kulturarbeidarar, er det rimeleg å omtale dette som ei effektiv form for kulturdiplomati med effekt langt inn i det ordinære diplomatiske arbeidet.

Andre sentrale nordmenn involvert i 1889-utstillinga var kunstnarane Edvard Munch og Erik Werenskiold. Mellom anna fekk Werenskiold gullmedalje for måleriet "En bondebegravelse". Trass i alt arbeidet med å profilere Noreg som ein rik, men på same tid moderne kulturnasjon, var likevel ikkje alltid den norske sjølvkjensla like god. Etter å ha besøkt verdsutstillinga og samanlikna dei norske innslaga med dei av meir vel etablerte kulturnasjonar, rapporterer den norske diktarhøvdingen Arne Garborg korleis det verkeleg sto til: 
Men naar ein hadde vore i dei andre Avdelingarne og so sidan kom inn i den norske att, saag ein, at Norig er eit fatigt Land. Alle Bilæte var so smaae, so knapt tilskorne, so knipne. Maalaranne vaare hev nok ikkje Raad til aa maala paa store Dukar. (Garborg 1890)

Likevel, stikk i strid med Garborg sin dom, fekk utstillinga med norske kunstnarar for det meste positiv respons blant utanlandske kritikarar. Kanskje særleg interessant er at mange av dei nettopp framstiller den norske kunsten som representativ for ein moderne, progressiv nasjon, fri frå dei normative føringane som kjem med ein tung (europeisk) kulturarv (Brenna 2002: 400).

Det uformelle norske diplomatiet i tida etter 1814, dominert av markante kunstnarar, vitskapsmenn og næringslivsfolk, utgjer altså det fyrste dømet på ein kulturdiplomatisk diskurs der ein kan hevde at tenkinga og praksisen er medveten og eksplisitt. Etter dette gjekk norsk kulturdiplomati imidlertid mange stille år i møte, så frå desse tidelege døma på kulturdiplomati hoppar eg seks tiår fram i tid.

\section{Den instrumentelle æraen}

I 1950 vedtok Stortinget å opprette Kontoret for kulturelt samkvem med utlandet som ei avdeling i Utanriksdepartementet. Oppgåvene som blei tillagt kontoret, hadde inntil no vore spreidd på Sosialdepartementet, Kyrkje- og undervisningsdepartementet og Utanriksdepartementet. Ved å samle den kulturelle innsatsen overfor utlandet på ein stad, håpa ein no både å rasjonalisere og effektivisere denne aktiviteten (Kolsrud 2008). Ifølgje Kolsrud hadde ein i utgangspunktet tenkt seg eit norsk institutt for kulturelt samkvem med utlandet, heilt eller delvis finansiert med midlar frå næringslivet. Men deira interesse synte seg å vere laber, og desse planane blei skrinlagde. Mot 30 stemmer frå Bondepartiet og Høgre løyvde Stortinget 10. mai 1950 dei bortimot 650000 kronene regjeringa hadde bedt om (Budsjettinnstilling nr. 18 (1950) St.tid. 1950: 921 ff. i Kolsrud 2008). Med dette kontoret blei ansvaret for all statleg norsk utanrikskulturell verksemd i praksis flytta til Utanriksdepartementet, der det sidan har blitt verande.

Denne administrative nyskapinga blei imidlertid ikkje til i eit nasjonalt politisk eller sosialt vakuum. I åra mellom fyrste og andre verdskrig såg ei rad europeiske statlege og halvstatlege institusjonar med kulturdiplomati og internasjonalt kulturelt samarbeid som virkeområde dagens lys, med det franske Relations culturelles et oeuvres françaises à l'étranger som det fyrste i 1923. British Council, Goethe-Instituttet, Det Danske Selskab og Svenska Institutet fylgde så, med Svenska Institutet som det siste i 1945. Dette førte til at også norsk UD mot slutten av 1940-talet konkluderte med at deira kulturdiplomati, om det skulle nå dei politiske måla ein hadde sett seg, hadde behov for ei tilsvarande institusjonell eining. Kva var så desse måla?

Jo, 1950-talet, prega av lange skuggar frå to verdskrigar og ei gryande frykt knytt til ein ny, denne gongen kald krig, skulle på mange måtar syne seg å vere ein gyllen æra for kulturdiplomati. Ikkje minst fordi dette blei sett som ei svært velkomen 
tilnærming til fredeleg internasjonalt samarbeid for å bygge gjensidig tillit og kulturell forståing. Desse og liknande målsetjingar er klart i tråd med det som innleiingsvis blir referert som ein standard definisjon av kulturelt diplomati: "The exchange of ideas, knowledge, art and other aspects of culture between states and people in order to generate mutual understanding.» (Cummings 2003)

I aukande grad såg ein no også det kulturelle diplomatiet som ein reiskap for ulike former for (og grader av) propaganda, og frå midten av sekstitalet skifta Kontoret for kulturelt samkvem med utlandet, ifølgje historikaren Svein Ivar Angell, gradvis fokus frå å sjå internasjonale kulturelle relasjonar hovudsakeleg som eit middel for å bygge tillit, til å sjå slike relasjonar meir og meir som eit utgangspunkt for å drive strategisk informasjon om Noreg, særleg med utgangspunkt i handel- og næringspolitiske målsetjingar (Angell 2014). Fokuset dreidde med andre ord i retning av det Joseph Nye refererer til som soft power. Dette er m.a. aktivitet som på ulike måtar freistar å få andre nasjonar og folk til å dele dei same visjonane om oss og sjølvbileta me sjølv har, som dei me presenterer for dem (Nye 2004). Vridinga frå å sjå kulturdiplomati som fredsskaping til å nytte det til å betre Noreg si generelle stilling internasjonalt, reflekterer også godt ein av dei mest konsistente trendane i norsk kulturdiplomati heilt frå byrjinga: Den vedvarande kjensla av å vere ein underdog av ein nasjon heilt i den nordlege utkanten av Europa (jf. Leira et. al. 2007, Teodora 2015). Eller det Christopher Browning presist refererer til som small state identity (Browning 2006).

I det norske kulturlivet, eit felt elles karakterisert av ein vedvarande skepsis mot instrumentell bruk av kunst og kultur (Mangset \& Hylland 2017), møtte utviklinga mot eit stadig meir instrumentelt fokusert kulturdiplomati lite anna enn ein kjøleg mangel på interesse. Kulturpolitisk var dette ei tid for eit intenst internt fokus. Sjølv om internasjonal kulturutveksling og -samarbeid, særleg i form av impulsar utanfrå, nok blei sett som viktig, såg mange samstundes slik aktivitet som eit forstyrrande og konkurrerande element i kampen for å bygge landet kulturpolitisk. Å arbeide for å etablere viktige nasjonale institusjonar, og politiske tiltak og verkemiddel på heimebane, som t.d. Norsk kulturråd, Rikskonsertane, Riksteateret osb., blei difor sett som langt viktigare enn å jobbe for å nå utanlandsk marknad og publikum. I den grad norske kunstnarar var med på offentlege oppdrag i utlandet, var det difor meir i form av einskilde oppdrag enn som del av ei systematisk utanrikskulturell satsing. Dessutan var dette ofte snakk om dei same kunstnarane, faktisk til ein slik grad at fleire av desse fekk den medvetne nedsetjande merkelappen diplomatisk kunst på virket sitt (Mangset 1997). Samstundes, og her kan ein tenkje seg at det finst ein samanheng, er døma på norske kunstnarar med internasjonal suksess frå denne tida relativt få, særleg om ein samanliknar med naboland som Sverige, Danmark og Finland. Der den svenske jazzsongaren Monica Zetterlund reiste til New York for å spele inn plater og konsertar med Bill Evens, heldt norske musikarar seg stort sett heime. Når skandinavisk design blei eit internasjonalt omgrep, var det danske Arne Jacobsen og finske Alvar Aalto som leia an, og så vidare. 


\section{Kulturpolitiske målsettingar inn i utanrikspolitikken}

I 1985 blei UD sin svært instrumentelle praksis med omsyn til bruk av kultur og kunstnarar endeleg utfordra. Etter fire års arbeid leverte det UD-oppnemnde Berg-utvalet sin omfattande NOU-rapport, Norges offisielle kultursamarbeid med utlandet. Medlemmane i komiteen var ikkje kven som helst. Til dømes var statsråd Lars Roar Langslet medlem frå starten i 1981 og fram til han blei erstatta i 1982, då han blei Noregs fyrste kulturminister i Willoch-regjeringa sitt nyoppretta kulturdepartement. I motsetnad til kva ein kanskje skulle tru, kom opprettinga av det nye Kulturdepartementet til å få lite å seie for den norske utanrikskulturelle verksemda, $i$ alle fall med omsyn til at denne skulle bli meir sjølvmedveten og eksplisitt. Mest av alt på grunn av at det utanrikskulturelle heilt sidan byrjinga på 1950-talet i så stor grad var plassert trygt nettopp i UD (jf. Solhjell 2006). Ein kan her dessutan skyte inn at etableringa av eit eige kulturdepartement i praksis var mindre tydingsfullt enn ein skulle tru. Alt frå 1819 hadde kulturpolitikk vore eit viktig saksområde innan Kyrkje- og utdanningsdepartementet, og ein kan hevde - i tråd med kulturpolitikkforskarane Mangset og Hylland (2017) - at dei fleste kulturpolitiske bedriftene verd å nemne var på plass alt før opprettinga av kulturdepartementet i 1982.

Berg-utvalet sin NOU i 1985, derimot, representerte noko nytt. Fyrst og fremst ved å eksplisitt tilrå å inkludere kulturpolitiske målsettingar i den utanrikskulturelle politikken. Særleg peika utvalet på at ein fram til da ikkje hadde hatt som eit eige mål å stimulere norsk kunst og kultur, ei heller norske kunstnarar eller kulturarbeidarar sine internasjonale ambisjonar, med andre ord det ein med Mangset kan omtale som «reine» kulturpolitiske målsettingar (Mangset 1997). Mellom anna skriv utvalet:

Utvalget vil imidlertid understreke at ikke noen gang er det tatt initiativ til å innrette kultursamarbeidet også etter det formål å stimulere norsk kultur- og samfunnsliv og kulturarbeidernes utviklingsmuligheter. (Berg 1985: 12)

Som ei følgje av dette rådde dei vidare til å flytte den utanrikskulturelle verksemda frå UD og over i ein separat institusjon med eit tilhøyrande fond, lausleg knytt til det nyoppretta Kulturdepartementet.

UD avslo resolutt utvalet sitt forslag om ein separat institusion. Det same gjorde utanrikskomiteen i Stortinget i si påfølgjande handsaming, men likevel ikkje utan å medgje at den internasjonale kulturpolitikken potensielt kunne bli skadelidande av det faktum at utanrikstenesta sitt diplomatiske personell både mangla spesialistkompetanse på kultur og jamleg bytter tenestestad og ansvarsområde. I den følgjande stortingsdebatten argumenterte Lars Roar Langslet, då nyleg avgått kulturminister, ivrig for å flytte ansvaret for utanriks kulturpolitikk $u t$ av UD:

Å la UD ta ansvar for norsk kulturrepresentasjon har gitt norsk kulturpolitikk «et unødig provinsielt preg» sier han. Det kulturelle er en «blindtarm innenfor UDsystemet». Vi burde ha lært, mener Langslet, at «profesjonell kulturformidling forutsetter et vel utbygd profesjonelt apparat. Det er dessverre få spor av en slik erkjennelse i den foreliggende melding.» (Forh. S. 1987-88: 3652, i Solhjell 2006: 64) 
Langslet blei ikkje høyrd av korkje Stortinget eller UD, og me måtte sjå eit nytt millennium før dette mønsteret blei brote.

Berg-utvalet sin NOU fekk truleg likevel ein viss effekt. Fleire teikn peikar mot slutten av 90-talet mot eit norsk kulturelt diplomati i ferd med å bli sjølvmedvete og eksplisitt på ein annan måte enn før. To akademiske bidrag reflekterer og dokumenterer dette. I 1997 kjem Per Mangset si bok Kulturskiller $i$ kultursamarbeid: om norsk kultursamarbeid med utlandet. Her skildrar han eit felt fullt av spenningar og konfliktar, prega av eit rigid og eigenrådig UD opphengt i forelda idear om instrumentell, utanrikskulturell politikk. Samstundes skildrar han eit kunstfelt i rask utvikling, i stadig tettare kontakt med ein internasjonal marknad og med ein aukande pragmatisk impuls til å integrere verksemda med Utanrikstenesta. I 1999 får vidare eit utval leia av Erik Rudeng mandat til å tenkje høgt kring kulturen si rolle i den norske utanrikspolitikken i eit nytt tusenår. I sin rapport, ført i pennen av Mette Lending, tilrår utvalet ei pragmatisk og multifokal tilnærming og rolleforståing. Her insisterer utvalet på at ulike perspektiv, dels knytt til kultur- og dels til utanrikspolitiske forståingar, ikkje treng å vere i konflikt. Lending skriv:

En avgiørende betingelse for en produktiv sameksistens mellom de to formålstypene er imidlertid at den instrumentelle argumentasionen utvides for å understreke at et bedre og mer moderne kunst- og kulturliv i seg selv er en sentral og legitim nasjonal interesse - som kan fremmes gjennom et offisielt kultursamarbeid med utlandet. (2000: 6)

Ein slik argumentasjon verka å falle i god jord hjå UD. Eller kanskje var tida berre mogen. I 2003 blir uansett store delar av UD si makt i utanrikskulturelle saker delegert på ein armlengds avstand frå departementet og ut til dei sju organisasjonane på kulturfeltet, ansvarlege for arkitektur og design, litteratur, visuell kunst, musikk, scenekunst, film og kunsthandverk. Desse, som raskt fekk tilnamnet forvaltarorganisasjonar, skulle med dette forvalte ressursane som tidlegare låg i departementet, til å støtte kunstnarar sine utanlandsreiser, utanlandske "ekspertar» sine reiser til Noreg for å bli kjende med norsk kunst- og kulturliv, prosjektmidlar, samt rådgje departementet i alle saker som omhandlar kultur. Det siste er ikkje det minst viktige, då det inneber ei direkte kopling mellom organisasjonane sin agenda og dei norske utanriksstasjonane sine prioriteringar innan kunst og kultur.

Med denne radikale endringa kan ein for alvor seie at kulturpolitikk og -diplomati blei ein eksplisitt del av norsk utanrikspolitikk, i den forstand at målsettingar også utan direkte instrumentell karakter sest som ein prinsipielt viktig komponent i den offisielle utanrikspolitiske diskursen. Det er elles interessant at dette skjer medan Jan Petersen sit som utanriksminister i Kjell Magne Bondevik si sentrumhøgre-regjering. Petersen, som ikkje kan skuldast for overdriven entusiasme for kulturdiplomati eller tru på soft power, kutta kraftig i budsjetta dei sju organisasjonane fekk i oppgåve å forvalte. Ein kan slik undre seg om outsourcinga av makt frå UD like gjerne var eit uttrykk for manglande interesse for kultur som for ein aktiv politikk, med ynskje om å imøtekome kulturfeltet sitt krav om ein meir profesjonell og 
mindre politisert forvalting av det utanrikskulturelle feltet. Nettopp det faktum at ministeren ikkje prioriterte kultur, gjorde at kulturdiplomatiet på sett og vis fekk ein meir autonom posisjon. I alle fall sett frå kunstfeltet si side.

Kva var det då som løyste ut denne endringa? Truleg kan generelle utanrikspolitiske straumar i retning av eit meir moderne diplomati vere ein del av forklaringa. Til dømes overgangen til eit meir mikro-orientert, såkalla «ope» diplomati, inspirert av ei angloamerikansk public diplomacy-tenking (Hayden 2011, 2013, Leira et. al. 2007, Matlary 2002). I St.meld. nr. 15 (2008-2009), Interesser, ansvar og muligheter Hovedlinjer i norsk utenrikspolitikk, blir ope diplomati forklart som lekk i å skulle «forstå, informere, påvirke og bygge relasjoner direkte til befolkninger, eller mer målrettet til utvalgte samfunnsgrupper.» I denne tenkinga, som nådde sitt klimaks om lag med utgjevinga av stortingsmeldinga nemnt over, var kunstnarar og kulturarbeidarar tenkt å kunne gjere ein jobb på line med høgt profilerte byråkratar, politikarar og diplomatar.

Samstundes hadde UD fått tilstrekkeleg distanse til Berg-utvalet sitt opprørske forslag om ekstern styring til at ein no kunne akseptere tanken om eit desentralisert ansvar for det utanrikskulturelle. Dessutan var den lett uinteresserte ministeren Petersen no erstatta av ein svært ivrig Jonas Gahr Støre. Aldri hadde vel UD sett ein minister med slik tru på og interesse for kultur, både som bidrag til eit effektivt og moderne diplomati og som progressivt karriereval for norske kunstnarar. Dessutan fall denne utviklinga saman med ei anna viktig kulturpolitisk utvikling, nemleg Stoltenberg-regjeringa sitt program Kulturløftet, som hadde som fanesak å løfte kulturposten opp på $1 \%$ av Statsbudsjettet totalt. Dei auka løyvingane, og ikkje minst den betydelege entusiasmen i kulturfeltet løftet førte med seg, fekk òg effekt på det utanrikskulturelle feltet, m.a. med ei stadig aukande interesse for norsk kultureksport både blant kunstnarane sjølv og i samfunnet elles.

I 2013 fann Kulturdepartementet og UD endeleg saman i ein sams utforma strategi, i form av Meld. St. 19 (2012-2013) Regjeringens internasjonale kulturinnsats. Kritikarar peika på at også denne "nye» politikken hadde eit problematisk instrumentelt preg, ja, kanskje meir problematisk enn nokon gong, i og med at den no på sett og vis var gøymd bort i ei rad ikkje-instrumentelle visjonar og strategiar om kultureksport og kunstnarar sine moglegheiter på ein global arena (sjå t.d. Nissen 2012). Denne kritikken fekk likevel ikkje særleg tyngde. Norsk kulturliv fortsette sin internasjonale ekspansjon, og dei fyrste åra av det nye millenniet kunne ein skilte med internasjonale stjerner som Bjarne Melgaard, Jo Nesbø og Snøhetta.

\section{Ein eksplisitt sjølvmedveten utanrikskulturell politikk}

Etter som me no når vår eiga samtid, er det på tide å konkludere. Spørsmålet som stadig har stått i sentrum for diskusjonen, har vore: På kva tidspunkt er det me ser eit sjølvmedvete og eksplisitt norsk kulturdiplomati tre fram? I teksten har eg argumentert for at ein kanskje ikkje skal leite etter eitt tidspunkt, men heller rette fokus mot kva ein legg i omgrepa sjølvmedveten og eksplisitt. Med dette utgangspunktet har eg føreslått å knyte 
framveksten av det eksplisitte og sjølvmedvetne til fire historiske fortettingspunkt, som på ulikt vis kan seiast å vitne om ei slik utvikling. Under er desse plasserte på ei tidsline:

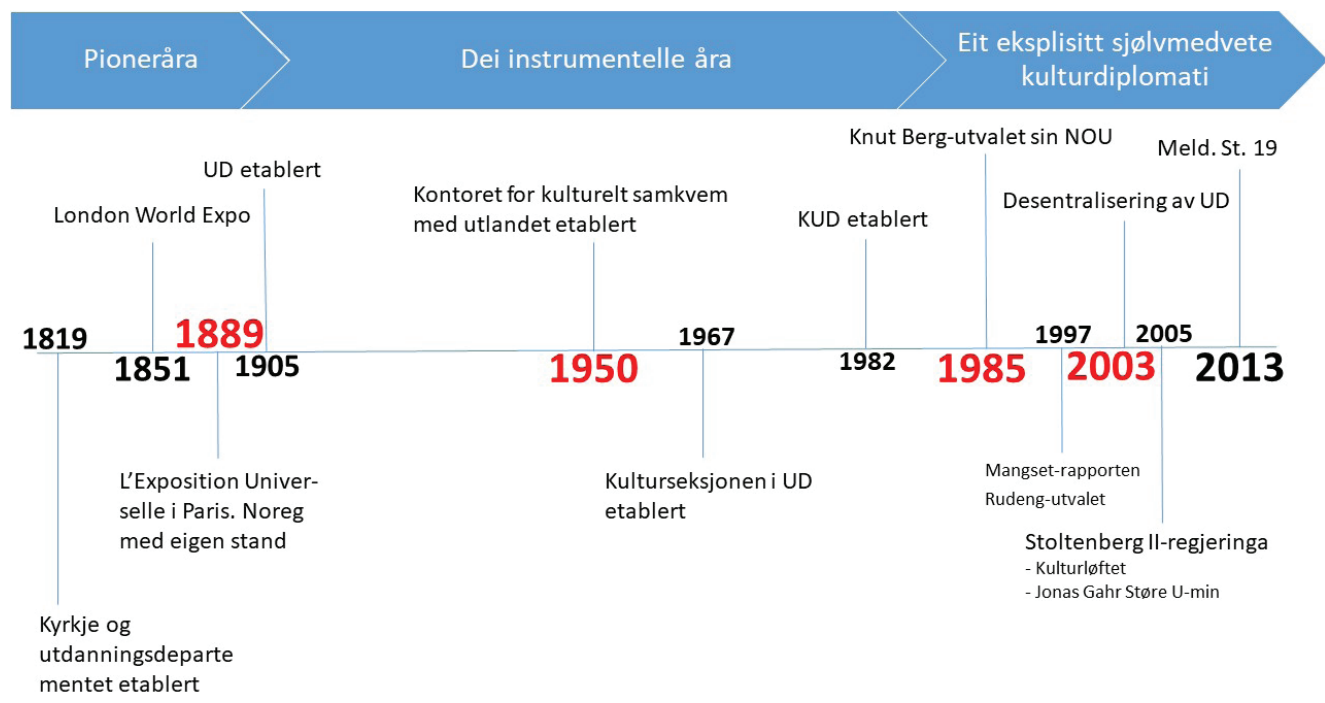

Var kulturdiplomatiet sjølvmedvete alt heilt frå starten av, den gongen diplomati og internasjonalt kulturelt samkvem meir eller mindre var ei og same sak? Det vil seie då kunst og kultur blei tenkt å eksplisitt representere nasjonal karakter og eigenart? Eller blei det det då UD fekk eit eige kontor for kulturelt samkvem med utlandet? Der kultur, trass i å vere del av ein instrumentell ideologi, likevel blei sett som ein viktig komponent $\mathrm{i}$ ein utanrikspolitikk med mål om å gjere verda meir forsonleg? Var det då kultur for kulturen si eiga skuld eksplisitt kom med som del av den utanrikspolitiske vokabularen, introdusert av Berg-utvalet? Altså då politikk som gjorde bruk av kultur blei supplert med ein som også såg kulturen sin eigenverdi? Eller var det fyrst då makta til å bestemme kva norsk kultur i ein utanrikspolitisk kontekst er, blei ført ut av UD og over i kulturfeltet, til organisasjonar som Office for Contemporary Arts Norway (OCA) og Music Norway? Altså då det norske kulturfeltet sjølv fekk vere med på å bestemme retning og innhald i utanrikskulturen; ei hending som vidare blei konsolidert og aksentuert i Meld. St. 19 i 2013, der det står svart på kvitt at kultur er ein fullverdig og legitim del av norsk utanrikspolitikk, heilt på line med andre sosiale, politiske og økonomiske samfunnsområde?

Desse fire nodalpunkta i norsk utanrikskulturell historie kan vidare knytast til kvar sin periode eller epoke, som ein kan sjå som særeigne diskursar. Dei har fătt namn som både refererer til dei punkta eg spesifikt har diskutert i teksten, men som også meir intuitivt kan vekke refleksjonar kring dette temaet. Pioneråra, dei instrumentelle åra og framveksten av (ikkje eit eksplisitt $o g$ sjølvmedvete, men) eit eksplisitt sjølvmedvete kulturdiplomati.

Dei tre epokane tar med andre ord utgangspunkt i ulike måtar som kultur kan sjåast som ein eksplisitt del av norsk diplomati og utanrikspolitikk. Dei representerer 
dermed også ulike perspektiv på kva det vil seie at kulturdiplomatiet er sjølvmedvete. For kunst- og kulturfeltet vil nok helst den siste epoken, der feltet sjølv inngår i verksemda på eigne premiss, oppfattast som eit gjennomslag. For tenestemenn og -kvinner i UD, på den andre sida, vil truleg eit slikt medvit heller knytast til epoken då Kontoret for kulturelt samkvem med utlandet blei oppretta og arbeidet med kultur ikkje blei flytta til Kulturdepartementet, trass i at mange kulturarbeidarar og -politikarar ynskte nettopp det. Slik sett vil svaret på det innleiande spørsmålet truleg vere meir avhengig av ei teoretisk enn ei empirisk betraktning. Dette svaret peikar dessutan mot eit skilje mellom dei som aksepterer instrumentell bruk av kunst og kultur i politikken og ikkje, sjølv om ein ikkje skal overdrive dette poenget. Særleg i det eg over kallar det eksplisitt sjølvmedvetne kulturdiplomatiet, er instrumentelle og kulturpolitiske rasjonalitetar så integrert, og aktørane så prega av ei pragmatisk tilnærming til praksis, at også eit slikt skilje verkar meir teoretisk enn empirisk fundert.

I den utanrikspolitiske retorikken, derimot, er kultur fråverande. Samstundes ser ein at Kulturdepartementet, saman med underliggande einingar som t.d. Kulturrådet, i aukande grad byrjar å snakke om utanrikskulturell politikk som del av sitt felt. Spørsmålet då er om outsourcinga av departementsmakt i 2003 var fyrste steg i retning av å etablere eit sjølvmedvete kulturdiplomati eller tvert om bidreg til å bygge ned kultur og kulturpolitikk som del av norsk utanrikspolitikk. Kanskje går utanrikskultur frå å vere implisitt utanrikspolitikk til å bli eksplisitt kulturpolitikk. Med det omfattande nettverket av utanriksstasjonar og eit diplomatkorps som i aukande grad syner interesse for kultur, ville det vere synd. Det ville dessutan vere starten på slutten på ein norsk utanrikskulturell tradisjon med svært lange anar.

\section{Om forfatteren}

Ola K. Berge er forskar ved Telemarksforsking, med utdanning frå Universitetet i Sørøst-Norge. Han har doktorgrad innan internasjonal kulturpolitikk, der han har studert norsk utanrikskulturell verksemd med fokus på UDs kulturpolitiske ansvar og praksis. Berge har jobba ved fagområde for kulturforsking ved Telemarksforsking sidan 2009. Faglege interesser er i tillegg til utanriks kulturpolitikk og generelle kulturpolitiske spørsmål, forsking i grenseland mellom populærkultur, kunstsosiologi og musikologi.

\section{Referansar}

Anderson, Benedict (1991) Imagined communities: reflections on the origin and spread of nationalism. London: Verso.

Angell, Svein Ivar (2014) Norsk kulturdiplomati under den kalde krigen: «Kontoret for kulturelt samkvem med utlandet». Universitetet i Bergen, Institutt for arkeologi (red.). UiO, Historiedagene 2014.

Belanger, Louis (1999) Redefining Cultural Diplomacy: Cultural Security and Foreign Policy in Canada. Political Psychology 20 (4): 677-699.

Berg, Knut (1985) Norges offisielle kultursamarbeid med utlandet. Norges offentlige utredninger 1985:12. Oslo: Universitetsforlaget.

Berge, Ola K. (2017) Look to NorwayTM. Current Norwegian foreign cultural policy. Ph.D.-avhandling, Universitetet i Sørøst-Norge. 
Bjørgo, Narve, Alf Kaartvedt \& Øystein Rian (1995) Selvstendighet og union: fra middelalderen til 1905. Norsk utenrikspolitisk historie, b. 1. Oslo: Universitetsforlaget.

Brenna, Brita (2002) Verden som ting og forestilling. Verdensutstillinger og den norske deltakelsen 1851-1900. Universitetet i Oslo: Universitetet i Oslo, Centre for Technology, Innovation and Culture.

Browning, Christopher S. (2006) Small, Smart and Salient? Rethinking Identity in the Small States Literature. Cambridge Review of International Affairs, 19 4/2006.

Cummings, Milton C. (2003) Cultural Diplomacy and the United States Government: a Survey. Washington: Center for Arts and Culture.

Dagsavisen (2017) Kjendisfest hos kulturministeren. 26.09.2017.

Gellner, Ernest (2006) Nations and nationalism. 2nd ed. New perspectives on the past. Malden, Massachusets: Blackwell.

Halmrast, Hanne H., Petter B. Refsli \& Jon Martin Sjøvold (2017) Kunst i tall 2016. Kulturrådet.

Hayden, Craig (2011) The Rhetoric of Soft Power: Public Diplomacy in Global Contexts, Rhetoric of Soft Power. Lanham: Lexington Books.

Hayden, Craig (2013) Social Diplomacy, Public Diplomacy, and Network Power. In Diplomacy, Development and Security in the Information Age, edited by Shanthi Kalathil. Edmund A. Walsh School of Foreign Service Georgetown University, Washington, DC: Institute for the Study of Diplomacy.

Hobsbawm, Eric J. (2012) Nations and Nationalism Since 1780: Programme, Myth, Reality: Cambridge University Press.

Kolsrud, Ole (2008) Rekonstruksjon og reform: regjeringskontorene 1945-2005. Riksarkivarens skriftserie, b. 430. Oslo: Universitetsforlaget.

Kulturdepartementet (2003) St.meld. nr. 48 (2002-2003) Kulturpolitikk fram mot 2014. Oslo: Kulturdepartementet.

Leira, Halvard, Axel Borchgrevink, Nina Græger, Arne Melchior, Eli Stamnes, and Indra Øverland (2007) Norske selvbilder og norsk utenrikspolitikk. Oslo: Norsk utenrikspolitisk institutt.

Lending, Mette R. (2000) Oppbrudd og fornyelse: norsk utenrikskulturell politikk 2001-2005. Aktuelle utenrikspolitiske spørsmål: rapport, b. 2:2000. Oslo: Utenriksdepartementet.

Mangset, Per (1997) Kulturskiller $i$ kultursamarbeid: om norsk kultursamarbeid med utlandet. Norsk kulturråds rapportserie, b. nr 9. Oslo: Norsk kulturråd.

Mangset, Per \& Ole Marius Hylland (2017) Kulturpolitikk: organisering, legitimering og praksis. Oslo: Universitetsforlaget.

Mark, Simon (2008) A Comparative Study of the Cultural Diplomacy of Canada, New Zealand and India. The University of Auckland.

Matlary, Janne H. (2002) Verdidiplomati - kilde til makt?: en strategisk analyse av norsk utenrikspolitikk. Rapportserien (Makt- og demokratiutredningen 1998-2003: trykt utg.), b. nr 46, august 2002. Oslo: Makt- og demokratiutredningen 1998-2003.

Neumann, Iver B. \& Halvard Leira (2005) Aktiv og avventende: utenrikstjenestens liv 1905-2005. Oslo: Pax.

Nisbett, Melissa (2012) New perspectives on instrumentalism: an empirical study of cultural diplomacy. International fournal of Cultural Policy, 19 (5): 1-19.

Nisbett, Melissa (2013) Protection, survival and growth: an analysis of international policy documents. International fournal of Cultural Policy, 19 (1): 84-102.

Nissen, Ada E. (2012) Kulturdiplomatene. Klassekampen. 30.08.2012.

Nye, Joseph S. (2004) Soft power: the means to success in world politics. New York: Public Affairs.

Rostgaard, Marianne (2011) Dansk kulturdiplomati over for Østblokken ca. 1960-1972. Historisk tidsskrift. 111 (2): 479-508.

Seip, Jens A. (1971) Ole facob Broch og hans samtid. Oslo: Gyldendal.

Solhjell, Dag (2006) Kuratorene kommer: kunstpolitikk 1980-2006. Oslo: Unipub.

SSB (2016) Utenrikshandel med varer. Eksport av varer, varegrupper etter SITC.

Teodora, Stefana (2015) Norway's Public and Cultural Diplomacy. Fournal of Global Politics and Current Diplomacy, 3 (1): 35-49.

VG (2017) Disse dukket opp på kulturministerens minglefest. 26.09.2017.

Waller, J. Michael (2007) The Public Diplomacy Reader: Institute of World Politics Press.

White, Candace L. (2012) Brands and national image: An exploration of inverse country-of-origin effect. Place Brand Public Dipl, 8 (2):110-118.

Wyszomirski, M. J., C. Burgess, and C. Peila (2003) International cultural relations: a multi-country comparison., Cultural Diplomacy Research Series. 


\begin{abstract}
English
At what point in history did Norwegian cultural diplomacy become self-conscious and explicit? In real terms, has culture or cultural policy ever been an integrated part of Norwegian foreign policy, or the foreign policy discourse? These are among the questions that are being discussed in this article, which moreover looks into how culture from early 1800 on was a central component of nation construction, and still is today. Hence, perhaps it is not such a long way from Norway's participation in the 1889 World Expo in Paris to how the Oslo opera house, drawn by Snøhetta architects, is profiled today. Still, the article concludes that a breakthrough for an explicitly self-conscious Norwegian cultural diplomacy somewhat paradoxically can be pinpointed to the period when the responsibility for Norwegian foreign cultural policy was moved out of the Ministry of Foreign Affairs, to a number of organizations within the art field. The text is an adaption of the trial lecture given as part of the defence of a Ph.D. in Cultural Studies at the University College of Southeast Norway, titled Look to Norway, current Norwegian Foreign Cultural Policy.
\end{abstract}

Keywords: cultural diplomacy $\cdot$ foreign cultural policy $•$ Ministry of Foreign Affairs 